\title{
SEISMIC PERFORMANCE OF HIGH STRENGTH CONCRETE FILLED HIGH STRENGTH SQUARE STEEL TUBES UNDER CYCLIC PURE BENDING
}

\author{
Guochang Li $^{1}$, Zengmei Qiu ${ }^{1,}{ }^{*}$, Zhijian Yang ${ }^{1}$, Bowen Chen ${ }^{1}$ and Yihe Feng ${ }^{2}$ \\ ${ }^{1}$ School of Civil Engineering, Shenyang Jianzhu University, Shenyang 110168, China \\ ${ }^{2}$ Liaoning Province Shiyan High School, Shenyang 110841, China \\ *(Corresponding author: E-mail: qzmfighting@126.com)
}

\section{A B S T RA C T}

To investigate the flexural behavior of high-strength concrete filled high-strength square steel tubes (HCFHSTs) under low-frequency cyclic loading, a test study was conducted on six HCFHSTs adopting different steel ratio. The objective of these tests was to analyze the failure modes, hysteresis curves, envelope curves, strength degradation, stiffness degradation, energy dissipation, and ductility of HCFHSTs. The results indicated that the HCFHST members had great performance, with highly saturated hysteresis curves, excellent energy dissipation capacity, and good ductility. Additionally, more models with different parameters were analyzed using the numerical analysis software ABAQUS, to determine the effects of the parameters on the flexural capacity and seismic performance of the HCFHST members with different steel yield strength (460-960 MPa), concrete compressive strength (60-110 MPa), and steel ratio. The ultimate flexural capacity, initial flexural stiffness, and serviceability-level flexural stiffness of the HCFHST members were calculated using the engineering design codes of several countries. The estimated results of the design codes were compared with the values obtained via the tests and numerical simulations to confirm the feasibility of various engineering design codes for calculating the flexural stiffness and ultimate flexural capacity of HCFHST members. This work will serve as a reference for future engineering design and broaden the applicability of engineering design codes.

\section{A R T I CLE H I S T O R Y}

$\begin{array}{ll}\text { Received: } & \text { 15 November } 2019 \\ \text { Revised: } & \text { 11 March 2020 } \\ \text { Accepted: } & \text { 13 March 2020 }\end{array}$

\section{K E Y W O R D S}

\author{
high strength; \\ pure bending; \\ steel ratio; \\ hysteretic behavior; \\ flexural stiffness
}

\section{Introduction}

All over the world, concrete filled steel tubes (CFSTs) are generally utilized in practical engineering applications owing to excellent load-bearing capacity, ductility, and fire resistance, along with their ease of use in construction. The rapid development of the construction industry has increased the seismic performance requirements of CFST members. To improve the utility of CFSTs in engineering, many researchers have investigated the mechanical behaviors of CFSTs worldwide. Furthermore, owing to the recent development and application of materials with high performance, researchers have studied the potential of high-strength steel (HSS) and high-strength concrete (HSC) for replacing conventional concrete and steel materials in CFST members. The use of high-performance materials in CFSTs can improve their load-bearing capacity and reduce their cross-sectional size, thus reducing the structural self-weight and the amplitude of the seismic response of the structural members. Therefore, the application of high-performance materials in CFSTs has considerable promise.

Thus far, numerous experimental studies and numerical simulations have been conducted on the axial and eccentric compression performance of CFSTs. For example, Uy et al. [1] performed numerous experimental analyses, where eight short composite HSS $\left(f_{\mathrm{y}}=761 \mathrm{MPa}\right)$-concrete columns and eight slender columns were tested. Li et al. [2-4] investigated the mechanism of HSC-filled square steel tube columns under axial and bi-axial eccentric loadings. Portolés et al. [5] carried out a test investigation of HSC-filled circular steel tubes under eccentric loading. Abramski [6] performed axial-compression experiments on 30 CFST columns with steel ratios between $4 \%$ and $6 \%$. Using a numerical analysis software, Ouyang et al. [7] studied the axial-compression performance of 92 square CFSTs, whose steel strength, concrete strength, and steel tube depth-to-thickness ratios were in the ranges of 24-110 MPa, 262-835 MPa, and 18-102, respectively. It was concluded that increasing the corner radius enhanced the post-peak behavior of the CFST columns.

The flexural behaviors of CFSTs have also been studied by numerous scholars. Elchalakani et al. [8,9] investigated the flexural behaviors of circular CFST members; it was observed that the filling of steel tubes within $\mathrm{D} / \mathrm{t} \leq 40$ with concrete delays local buckling failures. Lu et al. [10] performed pure bending tests and finite-element analysis on three rectangular CFSTs. The experimental data and finite-element analyses indicated that the flexural capacity of the rectangular CFSTs could be enhanced by $5 \%$ when the steel plate thickness ratio $\left(t_{2} / t_{1}\right)$ of the rectangular section ranged from 1.5 to 2.0. Chitawadagi et al. [11] investigated the strength deformation behavior of CFST specimens. According to the testing of 99 specimens with various in-fill concrete strength and $\mathrm{D} / \mathrm{t}$ ratios, an interaction model that relates the curvature of the CFST specimens to the applied bending moment was developed. Moon et al. [12] researched the mechanical behavior of CFST members via numerical analysis and compared the analysis results with design specification formulas. To calculate the moment versus drift curve of CFSTs subjected to pure bending, a simplified model was established. Zha et al. [13] derived the theoretical models for calculating the ultimate flexural capacity of concrete filled elliptical steel tube members. Wang et al. [14] performed pure bending experiments on CFSTs with different sections. It was observed that stress redistributions caused by the interactions between the steel tube and the concrete could enhance the load-bearing capacity of the CFST members. Montuori et al. [15] carried out a pure bending test investigation of CFSTs using HSS and constructed a corresponding finite-element model. Fu et al. [16] and Wang et al. [17] researched the bending resistance ability of circular concrete filled CFRP-steel tubes and lightweight aggregate CFSTs, respectively. Xu et al. [18] conducted axial compression and bending tests on hexagonal CFST members constructed using an HSC in-fill and different steel ratio. The behaviors of these CFSTs were then compared with those of hollow tubular members. On this basis, simplified models of the ultimate compression-bending capacity were proposed. Additionally, the plastic stress distribution method and the fiber model method can be adopted to predict the ultimate flexural capacity of CFSTs with hexagonal sections. Li et al. [19] analyzed the flexural behaviors of high strength concrete filled high strength square steel tubes (HCFHSTs) via experiments and numerical analysis, and compared the ultimate flexural capacity derived from the experimental research and numerical simulation method with the estimations of various design codes. The calculations of the EC4 specification were the most similar to the experimental/modeled values. Xiong et al. [20] conducted pure bending tests on eight CFSTs that used HSS with a yield stress of $780 \mathrm{MPa}$ and HSC with a compressive strength of $180 \mathrm{MPa}$. The maximum moment resistances obtained in these tests were compared with calculations based on the EC4 specification. According to their findings, they presented design proposals suitable for HCFHST members. Xie et al. [21] conducted bending and corrosion tests on 14 circular and square-shaped CFSTs filled with ordinary and recycled concrete. Pure bending experiments were performed by Chen et al. [22,23] on 28 circular CFAT members. As the thickness of the aluminum tube enhanced, the ductility and load-bearing capacity of CFATs improved. In contrast, the concrete strength had insignificant influence on the flexural behaviors or ductility of the CFATs.

Furthermore, the seismic performance of CFSTs has been investigated via experimental and finite element modeling approaches, on the basis of previous studies on the basic mechanical properties of CFSTs. Han et al. [24-27] performed a test study on the hysteretic behaviors of eight CFST specimens 
under cyclically increasing flexural loading with constant axial loads. On the basis of theoretical calculations, a simplified model was given to obtain the moment-curvature relationship, and a formula for calculating the ductility coefficient of CFST specimens was developed. Additionally, Han et al. analyzed the mechanical performance of 28 concrete-filled double skin steel tubes with different hollow sections and 18 HSC filled CFSTs with circular and square sections subjected to cyclically increasing flexural loading with constant axial loads. Elchalakani et al. [28] studied the hysteresis behavior of circular CFSTs and then compared the peak moments calculated from the test results with those predicted by various specifications. Thus, the new section slenderness was determined to limit the construction of earthquake-resistant structural systems. Liao et al. [29] had made suggestions for the design of the concrete-filled stainless steel tubular (CFSST) columns via testing 10 CFSST columns, according to the ultimate bearing capacity and flexural stiffness predicted using several design codes for CFSST specimens. Serras et al. [30] put forward a simple yet efficient model aiming to analyze the hysteretic behavior and load-bearing capacity of CFSTs and tested circular CFST specimens subjected to cyclically increasing flexural loading with constant axial loads. In numerous studies on CFST specimens with varying steel yield strength, concrete compressive strength and D/t ratio, the results indicated that the model reliably described the mechanical behaviors of the circular CFST specimens under cyclic loading. Chen et al. [31] studied the behavior of partially encased composite beams, concluding that the specimens under cyclic loads exhibited the excellent energy dissipation capacity, with equivalent viscous damping up to $49 \%$. A numerical analysis model was proposed by $\mathrm{Ma}$ et al. [32] to study the performance of hexagonal CFST members under cyclically increasing bending loads with a constant axial load. According to numerous parametric tests, a practical calculation method was developed for predicting the flexural capacity of hexagonal CFSTs.

As described previously, there are considerable research results regarding the static behavior of axially and eccentrically loaded CFSTs and the flexural behavior of CFSTs, and a few scholars have studied the hysteretic behavior of CFSTs subjected to cyclically increasing flexural loading with constant axial loads. However, there are very few reports on the hysteretic behavior of CFSTs under pure bending, particularly HCFHST members. Although CFSTs are rarely used as pure bending members in practical structures, the analysis of the seismic performance of CFSTs subjected to pure bending will provide useful insights to further study the functional mechanisms of CFST members under cyclically increasing flexural loading with a constant axial load. Moreover, all CFST related design codes around the world have specified limits for the scope of application of HSS tubes and HSC. In view of the foregoing, the hysteretic behavior of HCFHST members was investigated, and a parametric analysis was carried out adopting the simulation method. The ultimate flexural capacity, initial flexural stiffness, and serviceability-level flexural stiffness of HCFHST members obtained via experiments and numerical analysis were compared with the values calculated via the design codes of different countries, to determine whether these design codes are feasible for calculating the ultimate flexural capacity and flexural stiffness of HCFHST members. The findings of this study provide a reference for future engineering designs and broaden the applicability of engineering design codes.

\section{Experimental program}

\subsection{Test design}

Hysteresis tests were performed on six HCFHST members, which were divided into three sets. All the specimens had a length of $1500 \mathrm{~mm}$ and a cross-sectional area of $150 \mathrm{~mm} \times 150 \mathrm{~mm}$. The wall thicknesses of the steel tubes were 4,5 , and $6 \mathrm{~mm}$, and changes in the wall thicknesses were used to vary the steel ratio $(\alpha)$ of the specimens. The HSS square tubes were cold-formed steel tubes. The strength and elastic modulus of the steel materials were confirmed using the tensile tests specified in the GB/T228-2010 standard [33]. C100 HSC was used as the HSC in-fill of the HCFHST specimens. Standard concrete test cubes with dimensions of $150 \mathrm{~mm} \times 150 \mathrm{~mm} \times 150 \mathrm{~mm}$ were prepared for compressive-strength tests. According to the tests specified by the GB/T50081-2002 standard [34], the mean value of the compression strength of the cube specimens was $95 \mathrm{MPa}$. Steel plates with a thickness of 20 $\mathrm{mm}$ and a cross-section of $300 \mathrm{~mm} \times 300 \mathrm{~mm}$ were welded onto both ends of each HCFHST specimen. Details regarding the tested members are presented in Table 1.

Table 1

Parameters of the specimens

\begin{tabular}{|c|c|c|c|c|c|c|}
\hline Specimen & $B \times t \times L(\mathrm{~mm})$ & $\alpha$ & $f_{c u}(\mathrm{MPa})$ & $f_{y}(\mathrm{MPa})$ & $f_{u}(\mathrm{MPa})$ & $E_{s}(\mathrm{GPa})$ \\
\hline SPB1-1 & $150 \times 4 \times 1500$ & 0.116 & 95 & 434.56 & 546.2 & 206 \\
\hline SPB1-2 & $150 \times 4 \times 1500$ & 0.116 & 95 & 430.00 & 547.0 & 206 \\
\hline SPB2-1 & $150 \times 5 \times 1500$ & 0.148 & 95 & 416.31 & 513.7 & 206 \\
\hline SPB2-2 & $150 \times 5 \times 1500$ & 0.148 & 95 & 420.00 & 516.0 & 206 \\
\hline SPB3-1 & $150 \times 6 \times 1500$ & 0.182 & 95 & 430.00 & 545.0 & 206 \\
\hline SPB3-2 & $150 \times 6 \times 1500$ & 0.182 & 95 & 436.91 & 550.4 & 206 \\
\hline
\end{tabular}

Note: $B$ is the cross-sectional width. $t$ is the wall thickness of the steel tube. $L$ is the length of the member. $\alpha$ is the steel ratio. $f_{c u}$ is the compressive strength of the cube concrete. $f_{y}$ and $f_{u}$ are the steel yield strength and ultimate strength, respectively. $E_{S}$ is the Young's modulus of steel.

\subsection{Loading device}

An MTS hydraulic servo loading system was adopted to test the specimens. The cyclic loading was applied by a vertically set $100 \mathrm{t}$ MTS actuator situated at the mid-span position of the member, and then the MTS actuator was linked with a distribution beam via a set of rigid fixtures with the purpose of achieving pure bending loads. The specimens were horizontally placed in the middle of the loading system, and the boundary conditions on either side of the specimens were hinged connections. Because of the complex test equipment, a set of lateral supports was installed to prevent instability failure due to misalignment between the MTS actuator and the specimen axis. To allow the specimen to move freely in the vertical direction within the plane of the test equipment during the whole loading process, roller boards were welded onto the lateral supports. Two supports were tightly affixed to either side of the MTS actuator using screws. The bottom part of the supports was connected to an anchor via a beam, which limited lateral displacements of the member. The loading device is illustrated in Fig. 1. 

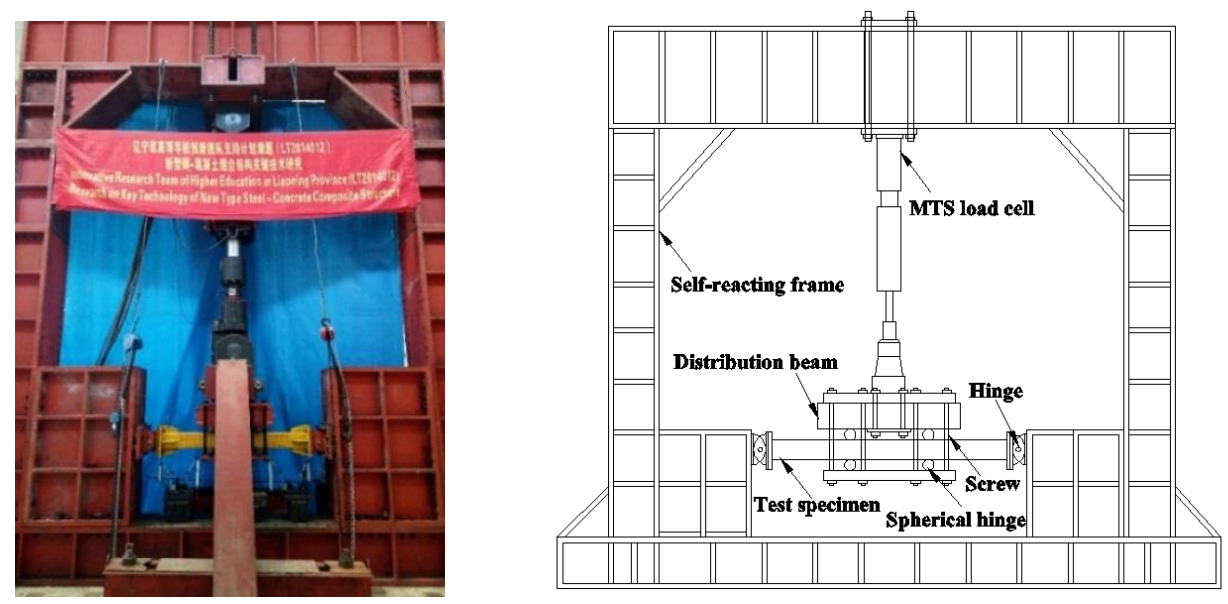

Fig. 1 Loading device.

\subsection{Measurement scheme}

Five displacement transducers were arranged in the mid-span, quarter-span, and endpoints of the HCFHST member to measure the deformation. Strain gauges were arranged on the top and bottom sides of the mid-span of the specimen to measure the strain on the surfaces of the steel tube, to study the constraining effects of the steel tube on the concrete. Strain gauges were also installed along the height of the specimen to study the change of the specimen's neutral axis. Fig. 2 shows the arrangement of the measuring devices.

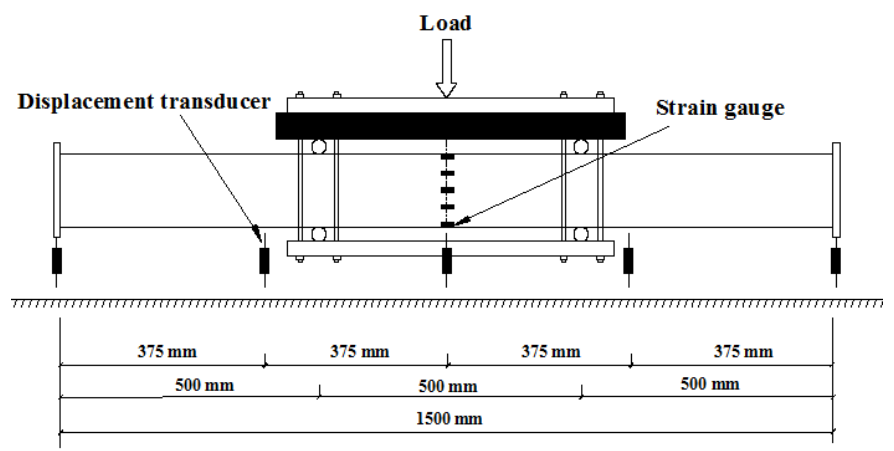

Fig. 2 Arrangement of measuring devices

\subsection{Loading procedure}

During the experiments, pre-loading was first performed to ensure that the test equipment and measuring instruments functioned properly. Fig. 3 presents the loading procedure of the HCFHST members, which comprised a load-control stage and a displacement-control stage. Prior to specimen yielding, force-controlled loading was used to load the specimen incrementally; the load was increased by approximately $20 \mathrm{kN}$ in each step, and each load level was cycled twice. Displacement-controlled loading was used after the specimen yielded. During this mode of loading, the loads were incremented stage-wise by $0.5 \Delta y$ or $1.0 \Delta y$ ( $\Delta y$ represents the yield displacement of the specimen). The specimen was cycled three times at the first three load levels and then cycled twice at all other load levels. The test terminated when the specimen could not bear additional loads or after the applied load decreased to $85 \%$ of the peak load.

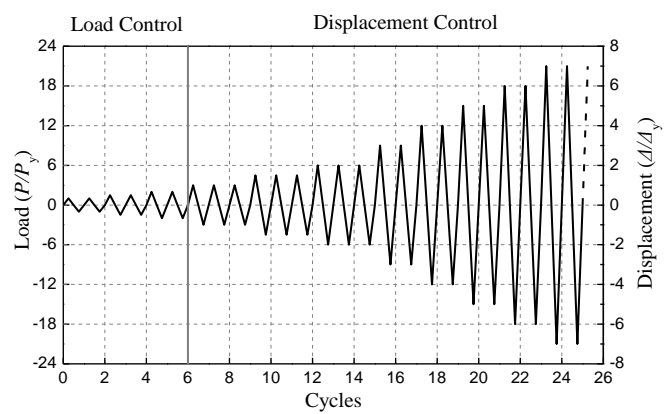

Fig. 3 Loading procedure

\section{Experimental results and specimen behavior}

\subsection{Loading process and failure mode}

The experimental loading procedure is described using specimen SPB1-2 as a typical specimen. Load control was used during the early stage of the experiment, where the member was still in elastic stage and did not exhibit significant bending deformation. As the applied load enhanced to $160 \mathrm{kN}$ and the displacement reached $11 \mathrm{~mm}$, the specimen began to yield. Displacement control was used beyond this point, and the load was $60 \%$ of the peak load at this point. When the load reached $2 \Delta y$, small concrete-cracking sounds were heard from inside the steel tube, and the increase in the load began to slow. When the load was $3 \Delta y$, clear and continuous concrete-cracking sounds were heard, and the inner side of the spherical hinge buckled slightly. When the load increased to $4 \Delta y$, the concrete-cracking noises became very loud, and the peak load was reached at this point. When the load was $5 \Delta y$, buckling deformation slowly spread around the outer side of the spherical hinge in a half-waved shape; slight buckling was appeared in the mid-span of the specimen. When the load increased to $6 \Delta y$, the area affected by buckling deformation near the spherical hinge gradually expanded, and the buckling deformations around the spherical hinge spread rapidly in the circumferential direction. When the load reached $7 \Delta y$, buckling deformations covered the entirety of the circumference near the spherical hinge, resulting in a lantern-shaped appearance. The continuation of the loading process caused the tension face (steel tube) near the spherical hinge to crack, which was accompanied by bits of crushed concrete falling out of the specimen. The experiment was terminated at this point. In particular, loading of specimen SPB1-1 was performed using a knife hinge on one end and a spherical hinge on the other end; the test of this specimen was terminated at $4.5 \Delta \mathrm{y}$, as the stress-concentrating effects of the knife hinge caused the specimen to crack prematurely. The failure modes of the other five specimens were similar. Similar to specimen SPB1-2 (whose failure mode is shown in Fig. 4), the other five specimens exhibited severe buckling near the spherical hinges, which caused the steel tube to crack.

After the loading tests, the outer steel tube of the HCFHST was separated from the specimens, for examining the damage of the concrete. Fig. 5 shows that concrete was crushed near the spherical hinges in specimen SPB1-2. This was caused by the concentration of stress near the spherical hinges. In the mid-span area, numerous transverse cracks appeared in the concrete. The concrete was crushed where buckling occurred in the steel tube.

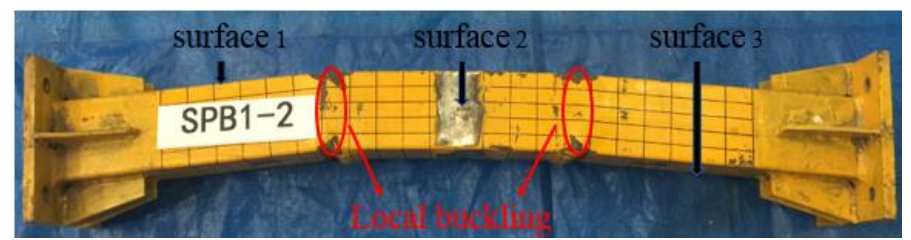

Fig. 4 Failure mode of the typical specimen 

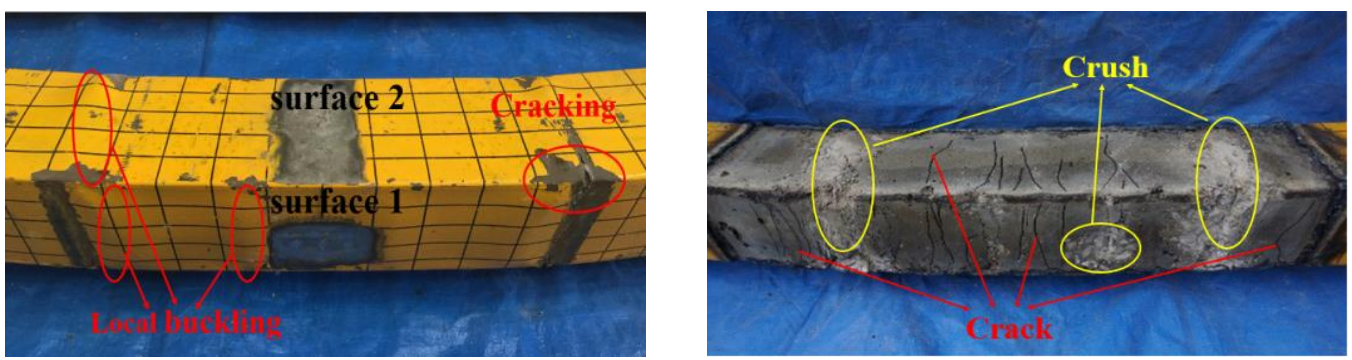

(a) Corners of the specimen
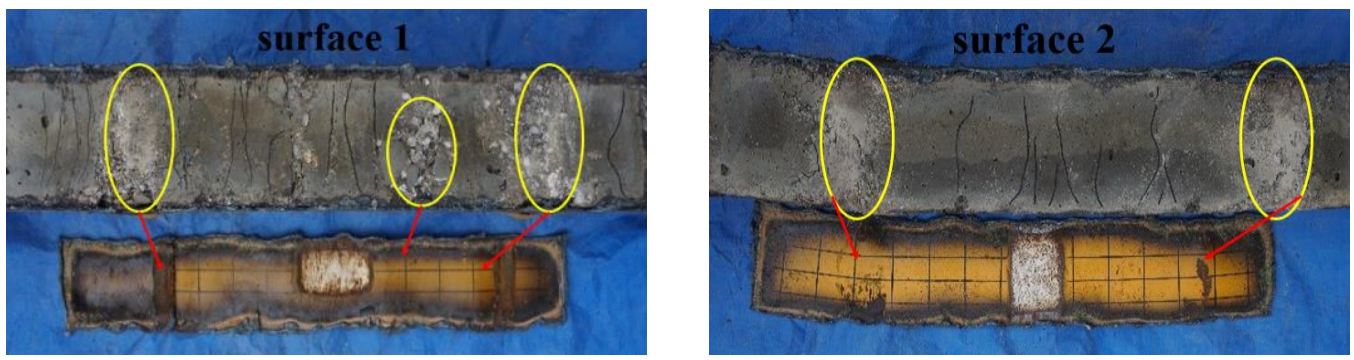

(b) Surfaces of the specimen

Fig. 5 Internal failure mode of the specimen

\subsection{Distribution of the deflection curves}

Fig. 6 illustrates the deflection of the HCFHST members at each level of pure bending load, along the length of each specimen. The dotted lines are

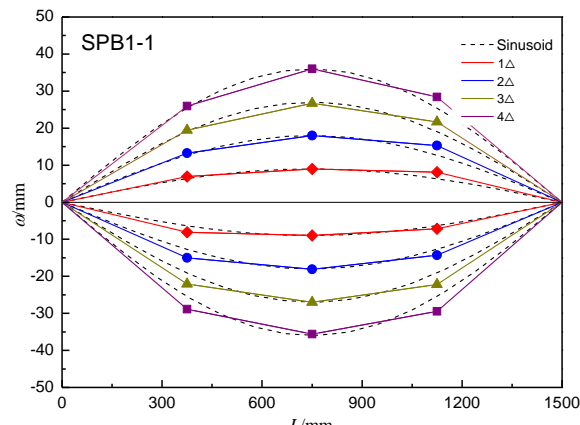

(a) SPB1-1

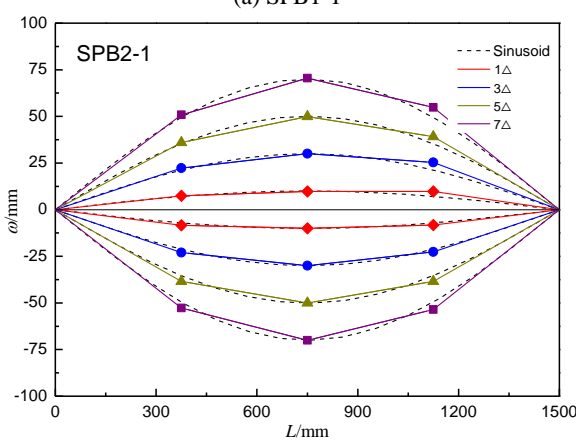

(c) SPB2-1

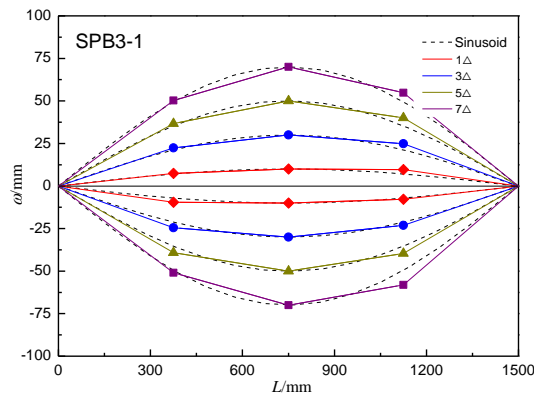

(e) SPB3-1 standard sinusoid curves. The horizontal and vertical axes represent the length of the specimen (L) and the deflection along the length $(\omega)$, respectively. The deformations of the HCFHST specimens generally conformed to the half-sine wave.

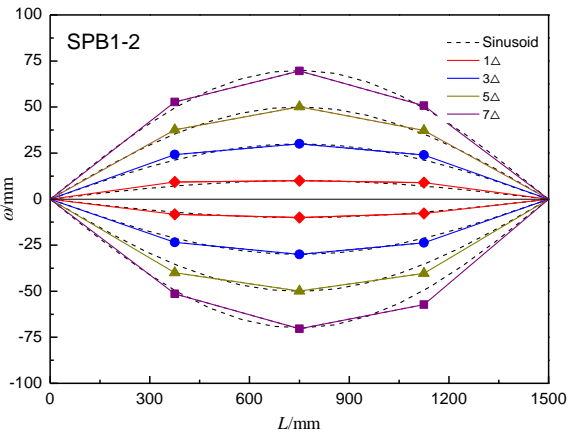

(b) SPB 1-2

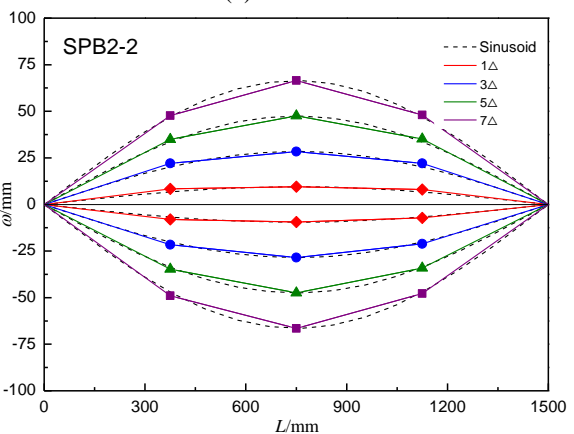

(d) SPB2-2

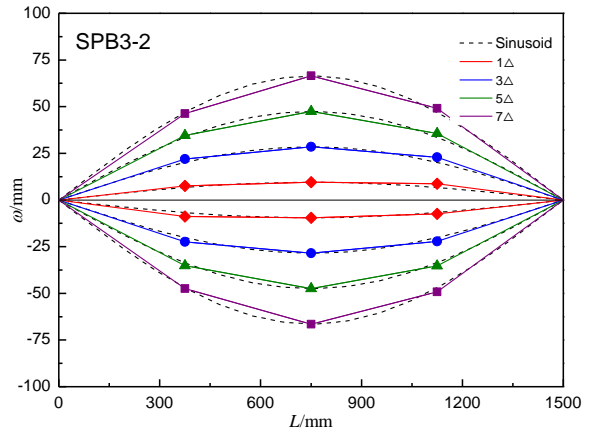

(f) SPB3-2

Fig. 6 Distribution of the deflection curves 


\subsection{Load versus displacement hysteretic curves}

The load versus displacement hysteretic curves of the HCFHST members under pure bending are shown in Fig. 7.

Before the specimen yielded, the displacement of the specimen changed linearly with respect to the load, as the member was still in elastic stage. Therefore, the area of the hysteresis loop formed by a single load cycle was relatively small, and the stiffness of the specimen did not change significantly during loading and unloading. The specimen entered the plastic stage after the yield point, which caused its stiffness to decrease slightly during the loading and unloading. With increasing load cycles, the stiffness decreased, but the area of the hysteresis loop enhanced.

The load versus displacement hysteresis loops of the HCFHSTs were highly full, as given in Fig. 7. Furthermore, the area of the hysteresis loops enhanced with the steel ratio, indicating an increase in the energy dissipation capacity. The bearing capacity of the specimens did not decrease significantly after reaching the peak load. Hence, the HCFHST specimens showed excellent seismic performance.

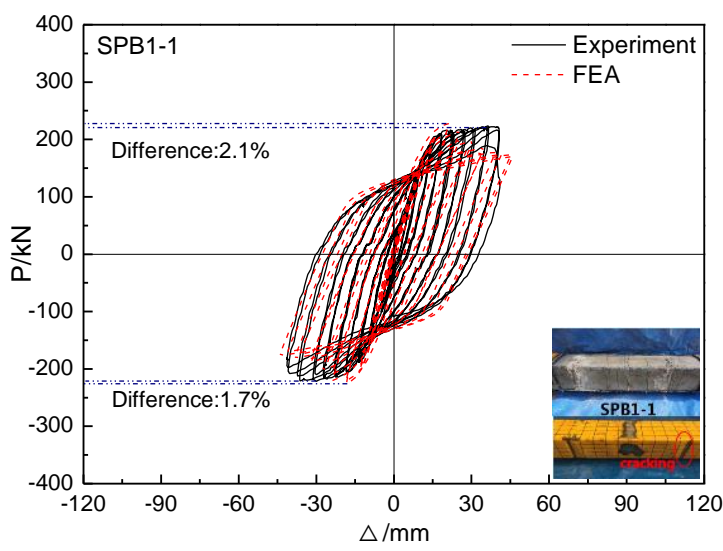

(a) SPB1-1

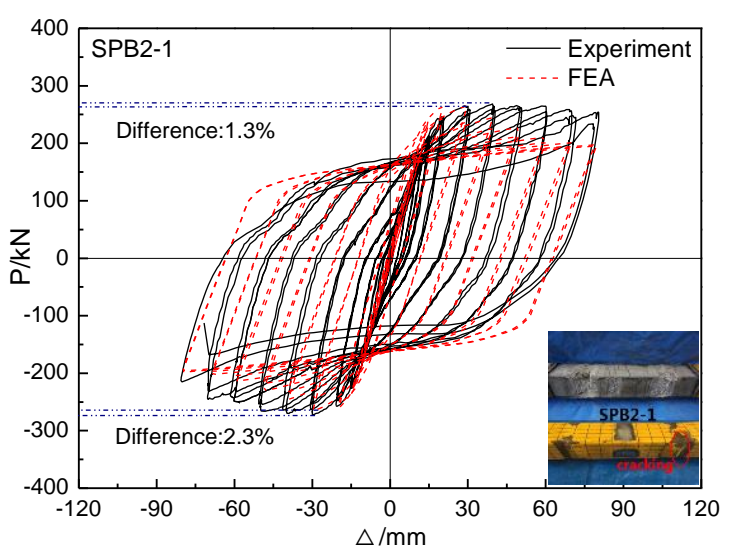

(c) SPB2-1

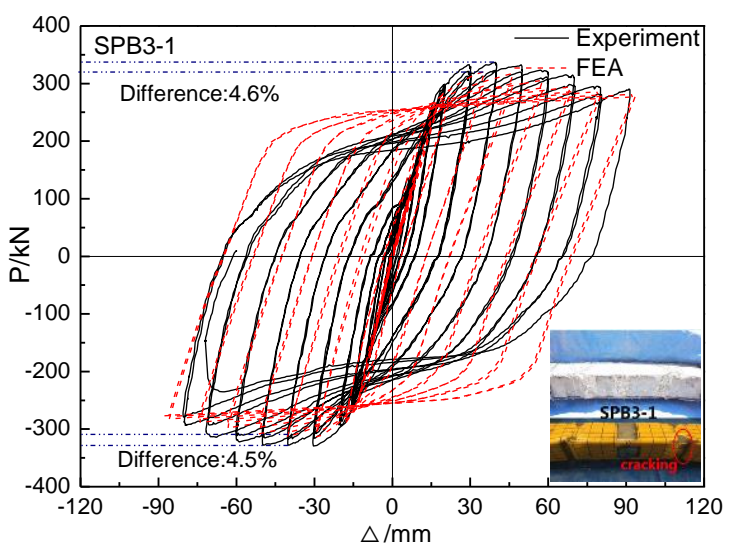

(e) SPB3-1

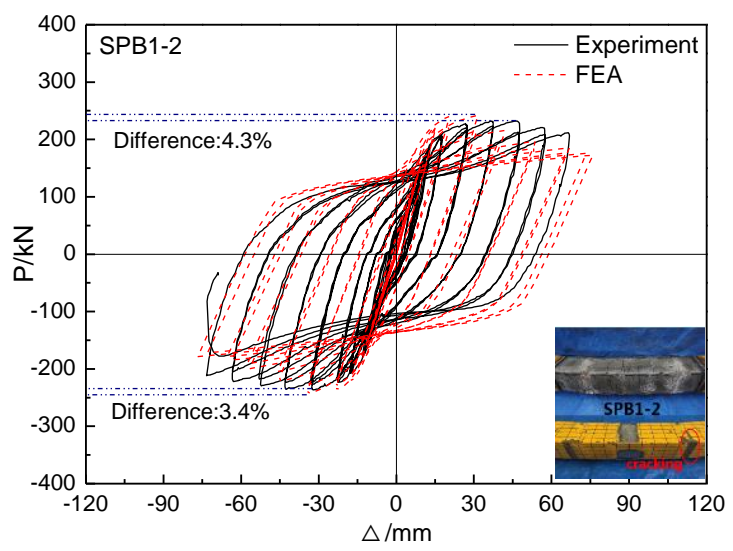

(b) SPB1-2

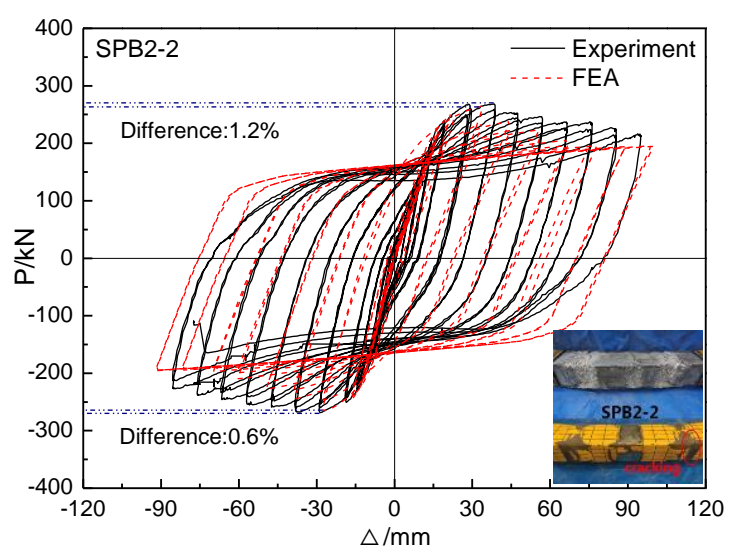

(d) SPB2-2

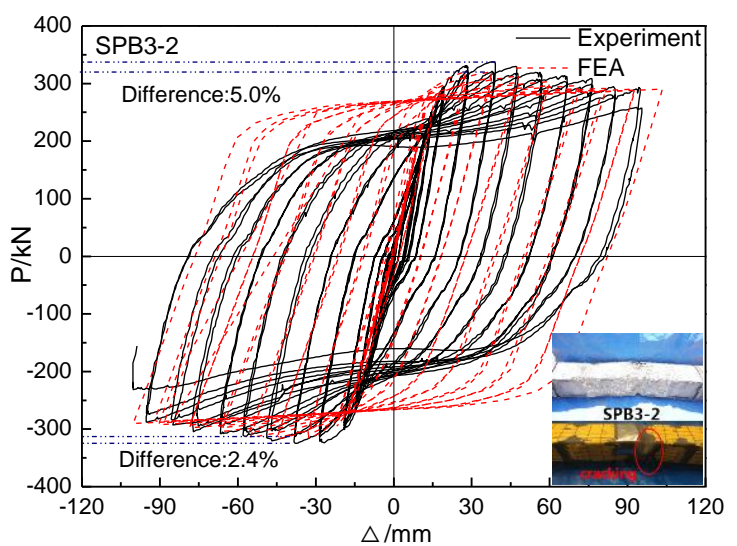

(f) SPB3-2

Fig. 7 Load versus displacement hysteretic curves

\subsection{Load versus displacement envelope curves}

As the load versus displacement envelope curve of the HCFHST member under pure bending did not exhibit a distinct yield point, the envelope curve can be simplified into a trilinear model, as given in Fig. 8. The yield displacement $(\Delta y)$ was calculated using the displacement corresponding to the intersection between the extrapolation of the elastic segment and the tangent line at the peak of the envelope curve. The ultimate displacement $(\Delta \mathrm{u})$ was calculated using the displacement of the point where the applied load decreased to $85 \%$ of the peak load or the displacement where specimen failure 
occurred.

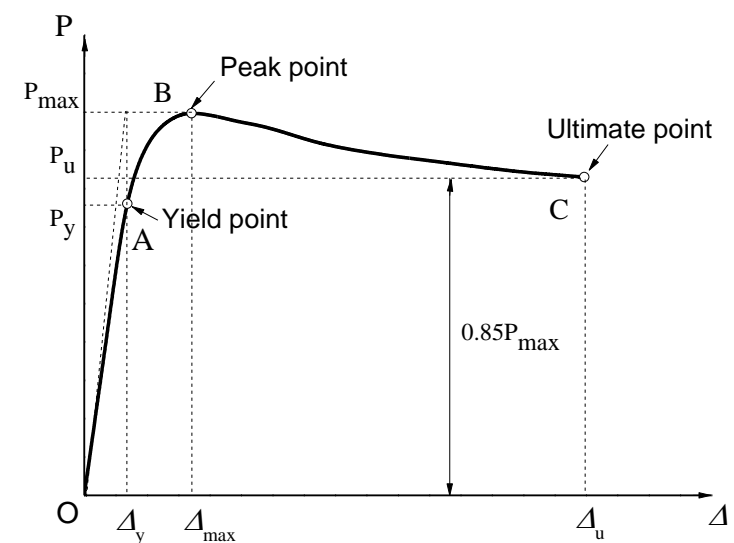

Fig. 8 Model of the trilinear envelope curve

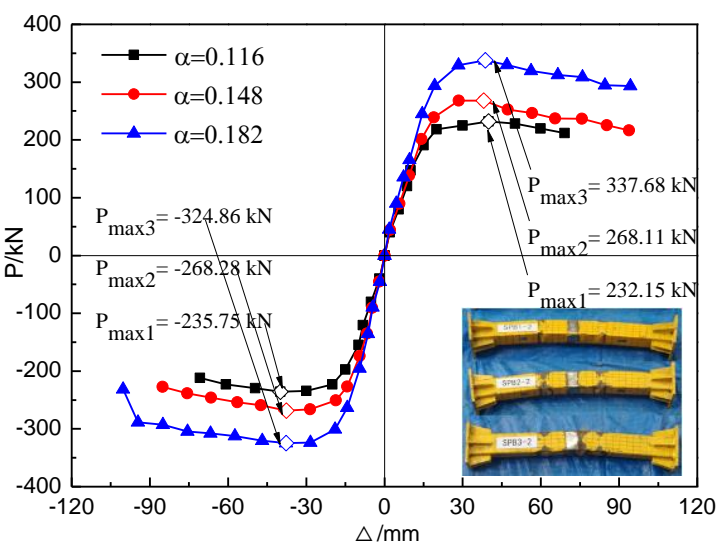

Fig. 9 shows the $\mathrm{P}-\Delta$ envelope curves of the HCFHST members, which can be divided into the following three stages.

1) Elastic stage: The bearing capacity increased linearly with respect to the displacement, and the envelope curve was linear, as the specimen was still elastic.

2) Elastic-plastic stage: The bearing capacity declined with an enhancement in displacement, and the envelope curve began to deviate from linearity. The bearing capacity increased slowly until the peak load was reached.

3) Post-yield stage: The bearing capacity decreased with an increase in the displacement, and the deformations of the specimen were large, resulting in stiffness degradation.

Table 2 presents the characteristic values of the envelope curve for each specimen. The envelope curves indicate that the HCFHST members had excellent ductility under pure bending, as throughout the loading process, significant degradations in the bearing capacity were not observed. The peak loads of these specimens significantly enhanced with the steel ratio: an enhancement in steel ratio from 0.116 to 0.148 increased the peak load of the HCFHSTs by approximately $17 \%$. When the steel ratio increased from 0.148 to 0.182 , the peak load of the HCFHST members increased by approximately $25 \%$. The peak load increased by approximately $45 \%$ when the steel ratio of the HCFHST members increased from 0.116 to 0.182 .

Fig. 9 Influence of $\mathrm{P}-\Delta$ envelope curves with different steel ratio

Table 2

Characteristic values of the specimens

\begin{tabular}{|c|c|c|c|c|c|c|c|c|}
\hline \multirow[b]{2}{*}{ Specimen } & \multirow[b]{2}{*}{ Loading stage } & \multicolumn{2}{|c|}{ Yield point } & \multicolumn{2}{|c|}{ Peak point } & \multicolumn{2}{|c|}{ Ultimate point } & \multirow{2}{*}{$\begin{array}{c}\text { Ductility } \\
\text { factor } \\
\mu\end{array}$} \\
\hline & & $\begin{array}{c}\Delta_{\mathrm{y}} \\
(\mathrm{mm})\end{array}$ & $\begin{array}{c}\mathrm{P}_{\mathrm{y}} \\
(\mathrm{kN})\end{array}$ & $\begin{array}{l}\Delta_{\max } \\
(\mathrm{mm})\end{array}$ & $\begin{array}{l}P_{\max } \\
(\mathrm{kN})\end{array}$ & $\begin{array}{c}\Delta_{\mathrm{u}} \\
(\mathrm{mm})\end{array}$ & $\begin{array}{c}\mathrm{P}_{\mathrm{u}} \\
(\mathrm{kN})\end{array}$ & \\
\hline \multirow{2}{*}{ SPB1-1 } & Positive & 11.88 & 172.70 & 36.18 & 223.64 & 40.50 & 220.18 & 3.41 \\
\hline & Negative & 9.22 & 151.24 & 30.96 & 221.59 & 40.59 & 206.46 & 4.40 \\
\hline \multirow{2}{*}{ SPB1-2 } & Positive & 11.87 & 163.33 & 39.96 & 232.15 & 69.12 & 211.92 & 5.82 \\
\hline & Negative & 11.04 & 164.62 & 39.90 & 235.75 & 70.78 & 211.62 & 6.41 \\
\hline \multirow{2}{*}{ SPB2-1 } & Positive & 12.63 & 180.34 & 39.48 & 268.66 & 80.24 & 254.28 & 6.35 \\
\hline & Negative & 10.96 & 183.09 & 39.70 & 272.26 & 74.58 & 231.42 & 6.80 \\
\hline \multirow{2}{*}{ SPB2-2 } & Positive & 12.24 & 174.30 & 38.07 & 268.11 & 83.10 & 227.89 & 6.79 \\
\hline & Negative & 12.15 & 203.59 & 37.68 & 268.28 & 84.33 & 228.04 & 6.94 \\
\hline \multirow{2}{*}{ SPB3-1 } & Positive & 11.22 & 197.88 & 39.60 & 336.80 & 91.04 & 290.51 & 8.11 \\
\hline & Negative & 11.46 & 202.97 & 40.02 & 329.39 & 79.13 & 293.10 & 6.91 \\
\hline \multirow{2}{*}{ SPB3-2 } & Positive & 13.61 & 232.15 & 38.66 & 337.68 & 94.35 & 293.26 & 6.93 \\
\hline & Negative & 11.80 & 227.10 & 37.77 & 324.86 & 94.57 & 288.38 & 8.01 \\
\hline
\end{tabular}

Note: $\mathrm{P}_{\mathrm{y}}$ and $\Delta_{\mathrm{y}}$ are the yield load and yield displacement, respectively. $\mathrm{P}_{\max }$ and $\Delta_{\max }$ are the peak load and peak displacement, respectively. $\mathrm{P}_{\mathrm{u}}$ and $\Delta_{\mathrm{u}}$ are the ultimate load and ultimate displacement, respectively. $\mu$ is the ductility factor.

\subsection{Strength degradation}

The strength degradation curve reflects the strength and deformation performance of a specimen under cyclic loading. Hence, it can be used to assess the overall strength degradation trends of a specimen and the degradation in the specimen strength at each load level. The overall strength degradation coefficient of a specimen $(\eta)$ is given by Eq. (1), and the strength degradation coefficient for each load level $(\beta)$ is given by Eq. (2).

$$
\eta_{i=} P_{i} / P_{\max }
$$

Where, $\eta_{i}$ is the overall strength degradation coefficient at the $\mathrm{i}^{\text {th }}$ load level, 
$\mathrm{P}_{i}$ is the maximum load of the $\mathrm{i}^{\text {th }}$ load level, and $\mathrm{P}_{\max }$ is the maximum value of the loading process.

$\beta_{i=} \mathrm{P}_{i}^{j} / \mathrm{P}_{i}^{l}$

Where, $\beta_{i}$ is the strength degradation coefficient of the $\mathrm{i}^{\text {th }}$ load level, $\mathrm{P}_{i}^{j}$ is the maximum load of the $\mathrm{j}^{\text {th }}$ cycle of the $\mathrm{i}^{\text {th }}$ load level, $\mathrm{P}_{i}^{l}$ is the maximum load of the $\mathrm{l}^{\text {th }}$ cycle at the $\mathrm{i}^{\text {th }}$ load level, and $\mathrm{j}$ and 1 are the second and first cycles of each load level, respectively.

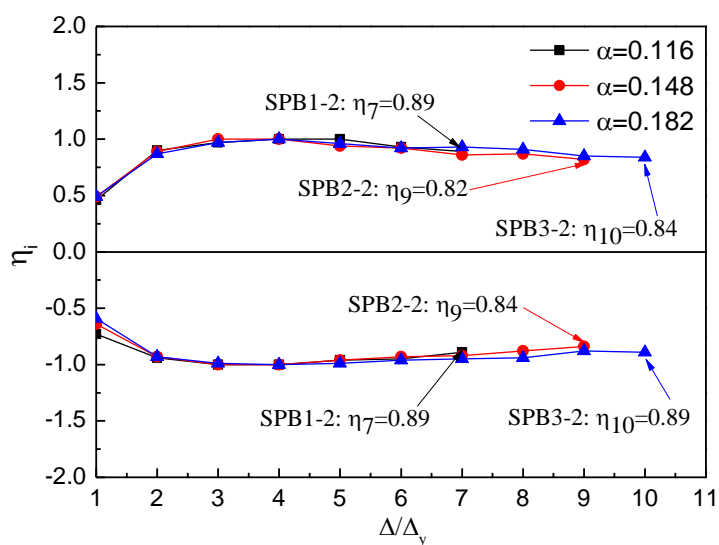

Fig. 10 Overall strength degradation curves

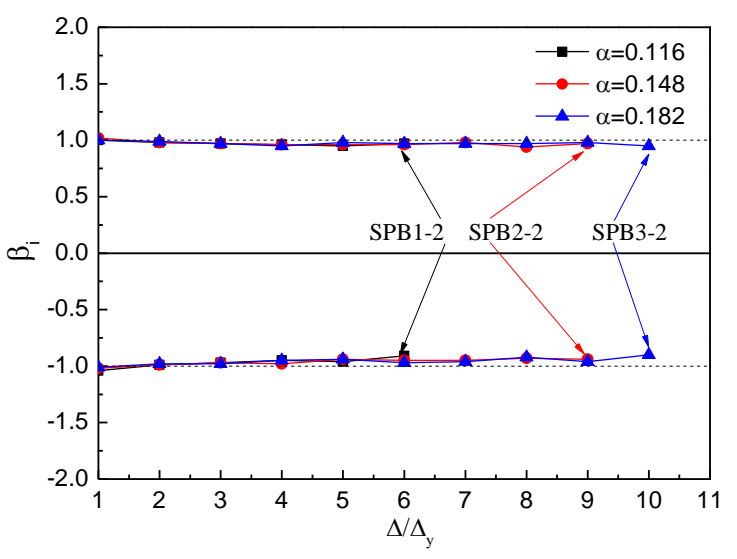

Fig. 11 Equivalent strength degradation curves

The overall strength degradation curves of members with several steel ratios are given in Fig. 10. The overall strength of each specimen increased with the load during the early stages of the loading. The strength degradation curve of each specimen trends downward in a linear fashion after the peak load, but the decrease in the strength appears to be insignificant. At the termination of the experiment, the overall strength degradation coefficients of the specimens ranged between 0.82 and 0.89 . This illustrates that the overall strength degradation of the members during the loading was not significant. The confinement effect of the steel tube prevented the concrete from splitting apart, which delayed the strength degradation and improved the seismic performance of the HCFHST members. Fig. 11 indicates that the strength degradation coefficient at each load level was close to 1.0 for the specimens. Hence, the bearing capacity of the specimens was relatively stable, and no specimen exhibited significant strength degradation at the same load level.

\subsection{Stiffness degradation}

Reductions in the bearing capacity of a specimen under cyclic loading are mainly caused by degradations in the specimen stiffness. Therefore, it is necessary to study the stiffness degradation curves of the members. In this paper, the stiffness (EI) of a member subjected to a pure bending load can be determined as follows:

$E I=\frac{M}{\varphi}$
Where, $\mathrm{M}$ is the moment, and $\varphi$ is the curvature.

The stiffness-degradation trends of the HCFHST members under pure bending are illustrated in Fig. 12. The Y-axis of this figure indicates the dimensionless $\mathrm{EI} /(\mathrm{EI})_{\text {first }}$ ratio, where $(\mathrm{EI})_{\text {first }}$ represents the stiffness of the member at the first loading level. The stiffness of the members continuously decreased with increasing in the displacement and cycle number, owing to the accumulation of damage. The degradation in the specimen stiffness was also due to continuous reductions in the elastic modulus of the concrete and steel materials. The stiffness degradation slowed after reaching the peak load, because the HSS steel tube confined the concrete and slowed its splitting, reducing the velocity of specimen stiffness degradation. Thus, the HCFHST members had excellent seismic performance. Fig. 12 also illustrates that the steel ratio had little effect on the stiffness degradation curves of members. Specimen failure generally occurred when the stiffness of the specimen decreased to approximately $11 \%-15 \%$ of the initial value.

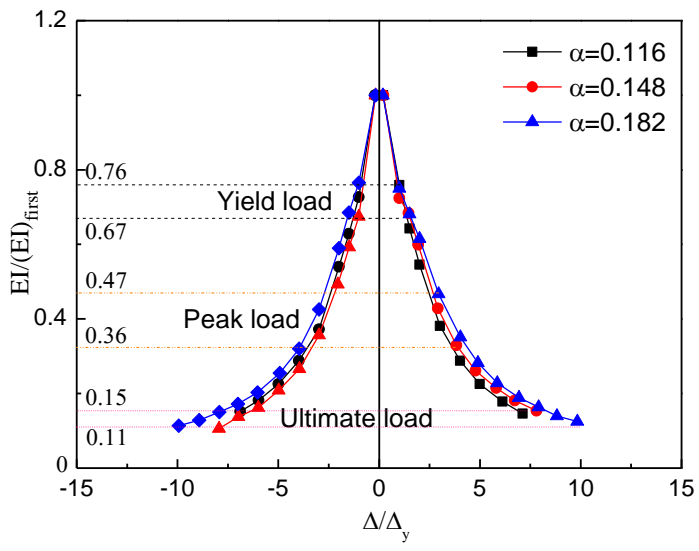

Fig. 12 Influence of stiffness-degradation curves with different steel ratio

\subsection{Energy dissipation capacity}

The energy dissipation capacity of members is usually determined via the equivalent viscous damping coefficient $\left(h_{e}\right)$. The larger value of $h_{e}$ indicates the better energy dissipation capacity of specimens. In this paper, $h_{e}$ was calculated using the last $\mathrm{P}-\Delta$ hysteresis loop prior to specimen failure, as indicated by Eq. (4). Fig. 13 shows the typical $\mathrm{P}-\Delta$ hysteresis loop of a member subjected to cyclic loading.

$h_{e}=\frac{E}{2 \pi}, \quad E=\frac{S_{A B C D A}}{S_{O B E}+S_{O D F}}$

Where, $E$ is the energy dissipation coefficient, $S_{A B C D A}$ is the area of the hysteresis loop in Fig. 13, and $S_{O B E}$ and $S_{O D F}$ are the area of the triangle in Fig. 13.

The area covered by $\mathrm{S}_{\mathrm{ABCDA}}$ represents the energy absorbed by the member in a single cycle, whereas $\mathrm{S}_{\mathrm{OBE}}+\mathrm{S}_{\mathrm{ODF}}$ represents the energy released by the member during the unloading process.

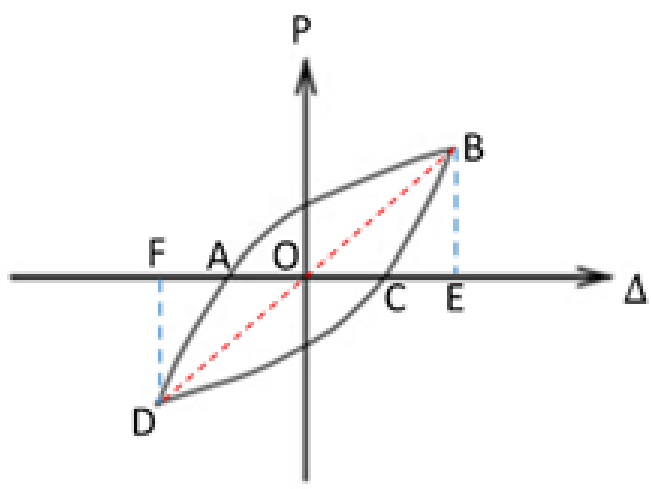

Fig. 13 Hysteresis loop of the load versus displacement curve 
Table 3

Energy dissipation

\begin{tabular}{|c|c|c|c|c|c|}
\hline Specimen & $S_{A B C D A}$ & $S_{\mathrm{OBE}}$ & $S_{O D F}$ & E & $h_{e}$ \\
\hline SPB1-1 & 16402.22 & 4435.45 & 4188.78 & 1.9019 & 0.3027 \\
\hline SPB1-2 & 29512.30 & 7323.96 & 7489.23 & 1.9923 & 0.3171 \\
\hline SPB2-1 & 39007.82 & 10042.71 & 8640.12 & 2.0879 & 0.3323 \\
\hline SPB2-2 & 43068.15 & 9485.04 & 9665.94 & 2.2489 & 0.3579 \\
\hline SPB3-1 & 53200.00 & 11694.38 & 11596.50 & 2.2842 & 0.3635 \\
\hline SPB3-2 & 62818.00 & 13834.54 & 13636.05 & 2.2867 & 0.3639 \\
\hline
\end{tabular}

In an HCFHST member subjected to pure bending loads, energy dissipation mainly occurs via crack propagation in the concrete, the development of plasticity in the steel tube, and contact between the concrete and steel tube. Table 3 presents the cumulative energy dissipation of each specimen. As shown, $h_{e}$ varied between 0.3027 and 0.3639 , and the energy dissipation capacity of the specimens increased with the steel ratio.

The $h_{e}$ versus $\Delta / \Delta_{y}$ plot of each specimen is presented in Fig. 14. As shown, $h_{e}$ increased with the displacement, indicating that the energy dissipation capacity of the members enhanced with the displacement. The growth of the $h_{e}$ versus $\Delta / \Delta_{y}$ curve began to slow after the peak load was reached, with $h_{e}$ decreasing slightly near specimen failure. This is because the energy dissipation capacity of members decreased when severe crushing and buckling occurred in the concrete and steel tube. During the early stage of loading, an enhancement in the steel ratio had no significant influence on the energy dissipation capacity of the specimens. However, after the peak load was reached, the energy-dissipation capacity increased by $11.4 \%(17.4 \%)$ when the steel ratio was increased from 0.116 to $0.148(0.182)$. This is because the confinement of the concrete by the HSS tube increased with an increase in the steel ratio, which enhanced the deformation capacity of the concrete and thus improved the energy dissipation capacity of specimens.

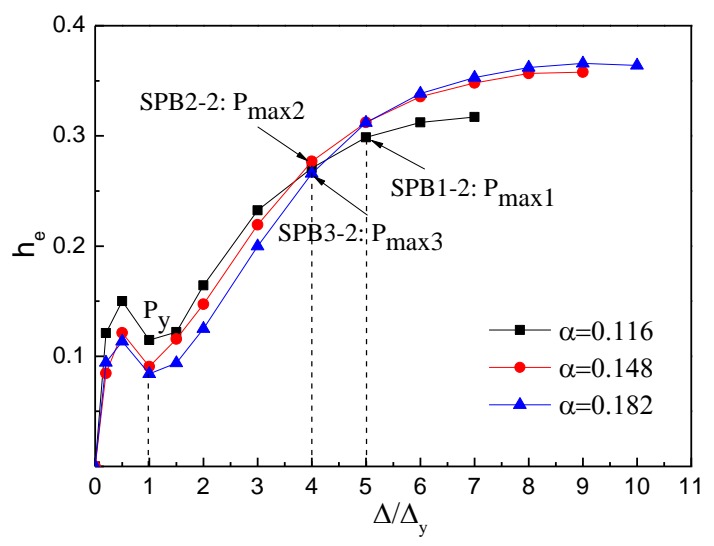

Fig. 14 Influence of energy-dissipation curves with different steel ratio

\subsection{Ductility}

The ductility of the HCFHST members was investigated according to the displacement ductility factor $(\mu)$, which was calculated as follows:

$\mu=\frac{\Delta_{u}}{\Delta_{y}}$

The $\mu$ values of the test specimens are presented in Table 2. An analysis of these data reveals that the specimens generally exhibited excellent ductility. Furthermore, the ductility performance of the HCFHST members improved with the steel ratio.

\section{Finite element analysis and discussions}

\subsection{Material}

4.1.1. Steel

The stress-strain curve of steel comprised two stages: an elastic stage and a hardening stage. The initial elastic modulus $\left(\mathrm{E}_{S}\right)$ was defined as the loading and unloading stiffness of the elastic stage, whereas the hardening modulus was defined as $0.01 \mathrm{E}_{S}$. To consider the influence of the Bauschinger effect on the loading and unloading processes of the HCFHST members, the bilinear kinematic hardening model was adopted to simulate the constitutive model of steel.

\subsubsection{Concrete}

The concrete model suggested by Han [35] was adopted to simulate the in-fill concrete. The equations are as follows:

$y= \begin{cases}2 x-x^{2} & (x \leq 1) \\ \frac{x}{\beta_{0}(x-1)^{\eta}+x} & (x>1)\end{cases}$

In which

$x=\frac{\varepsilon_{c}}{\varepsilon_{c 0}}, \mathrm{y}=\frac{\delta_{c}}{\delta_{c 0}}, \delta_{c 0}=f_{c}^{\prime}\left(\mathrm{N} / \mathrm{mm}^{2}\right)$

$\varepsilon_{c 0}=\varepsilon_{c c}+800 \xi^{0.2} \cdot 10^{-6}$

$\varepsilon_{c c}=\left(1300+12.5 f_{c}^{\prime}\right) \cdot 10^{-6}$

$\eta=1.6+1.5 / x$

$\beta_{0}=\frac{f_{c}^{0.1}}{1.2 \sqrt{1+\xi}}, \xi=\frac{A_{s} f_{y}}{A_{c} f_{c k}}=\alpha \cdot \frac{f_{y}}{f_{c k}}$

Where, $f_{\mathrm{c}}$ is the cylinder concrete strength, and $f_{\mathrm{ck}}$ is the characteristic concrete strength.

To account for degradations in the concrete stiffness that occur gradually during cyclic loading (resulting from the damage sustained by the concrete during cyclic loading), the concrete plastic damage model given by ABAQUS was used to simulate the mechanical behaviors of the concrete. The main parameters (the dilation angle $(\psi)$, the flow potential eccentricity $\left(e_{\mathrm{f}}\right)$, etc.) in the elastic damage model were obtained according to the work of $\mathrm{Li}$ [36]. The stiffness degradations induced by compressive and tensile damage were denoted as $\mathrm{d}_{c}$ and $\mathrm{d}_{t}$, which were calculated using Eqs. (7) and (8), respectively.

$$
\begin{aligned}
& \mathrm{d}_{c}=1-\frac{\left(\sigma_{c}+0.5 \sigma_{c 0}\right)}{E_{c}\left(0.5 \sigma_{c 0} / E_{c}+\varepsilon_{c}\right)} \quad\left(\mathrm{d}_{c} \geq 0\right) \\
& \mathrm{d}_{t}=1-\frac{\left(\sigma_{t}+0.5 \sigma_{t 0}\right)}{E_{c}\left(0.5 \sigma_{t 0} / E_{c}+\varepsilon_{t}\right)} \quad\left(\mathrm{d}_{t} \geq 0\right)
\end{aligned}
$$

In these equations, $\delta_{c}, \varepsilon_{c}$, and $\delta_{c 0}$ are the compressive stress, compressive strain, and uniaxial compressive peak stress of the concrete, respectively; $\delta_{t}, \varepsilon_{t}$, and $\delta_{t 0}$ are the tensile stress, tensile strain, and uniaxial tensile peak stress of the concrete, respectively. 


\subsection{Details of Finite Element Model}

The solid element C3D8R was employed to model the steel tube, the concrete, and the end plates of HCFHSTs. "Tie" constraint was used to simulate the contact between the end plates and steel tube. The relationship between the end plates and concrete in the normal direction was subjected to the hard contact. Between the steel tube and concrete, surface-to-surface contact was applied to model the interaction. The contacts in the normal direction were modeled as hard contact, whereas the tangential contacts were

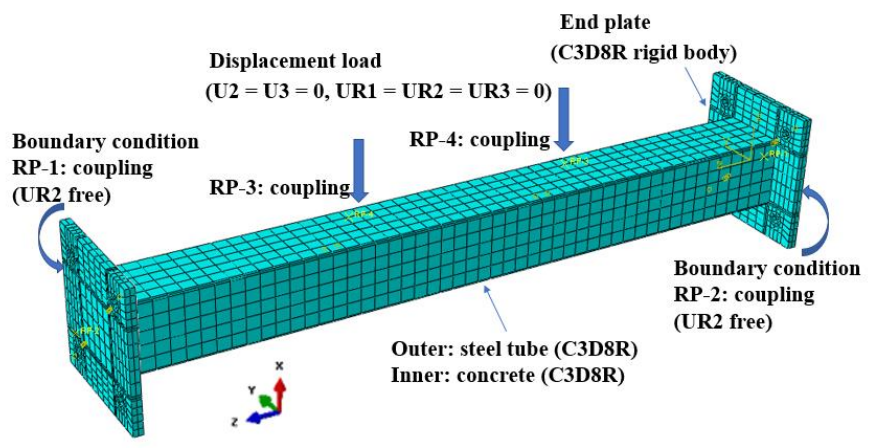

Fig. 15 Finite element model

\subsection{Model verification}

Fig. 7 illustrates the load versus displacement hysteretic curves of the HCFHST members obtained via simulations, which were compared with the experiment results. The results obtained via the numerical model agreed well with the experimental results, with errors of $<5 \%$.

\subsection{Parameters analysis}

The numerical analysis models were adopted to research the influences of various parameters (thickness of the steel tube, 4-6 mm; steel yield strength, 460-960 MPa; concrete compressive strength, 60-110 MPa) on the hysteretic behaviors of the HCFHST members under pure bending. The moment versus curvature $(\mathrm{M}-\varphi)$ envelope curves of the models are shown in Fig. 16.

\subsubsection{Steel strength}

As shown in Fig. 16(a), the steel strength did not significantly affect the elastic stiffness. This is because the elastic modulus of steel does not influence its strength. However, the yield moment and ultimate moment of the members increased with the steel strength.

\subsubsection{Concrete compressive strength}

The M- $\varphi$ curves of HCFHST members with several concrete compressive strengths under pure bending are given in Fig. 16(b). The results illustrate that the concrete strength did not affect the elastic stiffness or the yield moment. However, an enhancement in the concrete strength caused the downward trend in the bearing capacity after the peak load was reached to become more pronounced. This is due to the increases in the concrete strength are accompanied by increases in the specimen brittleness and reductions in the ductility.

\subsubsection{Steel ratio}

Fig. 16(c) illustrates the effects of the steel ratio on the $M-\varphi$ curves of the HCFHST members. The elastic stiffness, yield moment, and bearing capacity of the model enhanced with the steel ratio. This is because the confinement of the concrete by the steel tube was improved by increasing the steel ratio, which improved the deformation capacity of the HCFHST member and thus increased its bearing capacity and ductility. simulated adopting a Coulomb friction model with a friction factor of 0.6 [35].

During the simulation analysis of the HCFHST model, cyclic displacement loading was performed by defining the one-third points of the specimen as reference points. Additionally, kinematic constraints were imposed on the end plates of the HCFHST model to simulate the boundary conditions imposed by the hinge connections. The details of the numerical model are shown in Fig. 15.

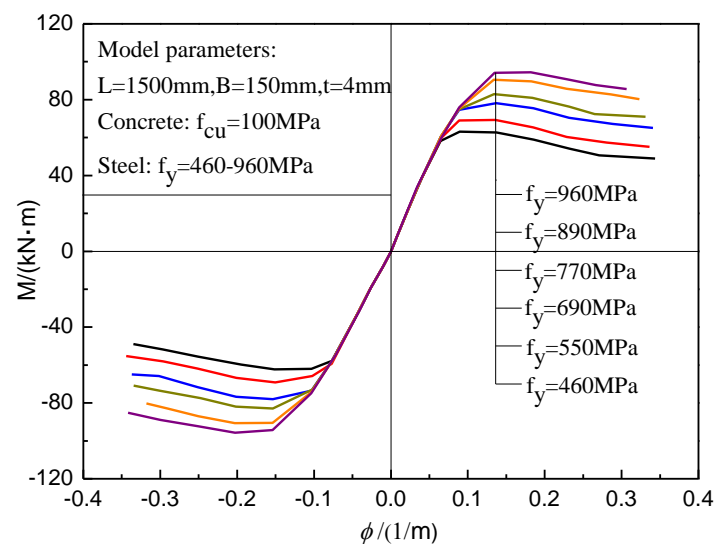

(a) Steel strength

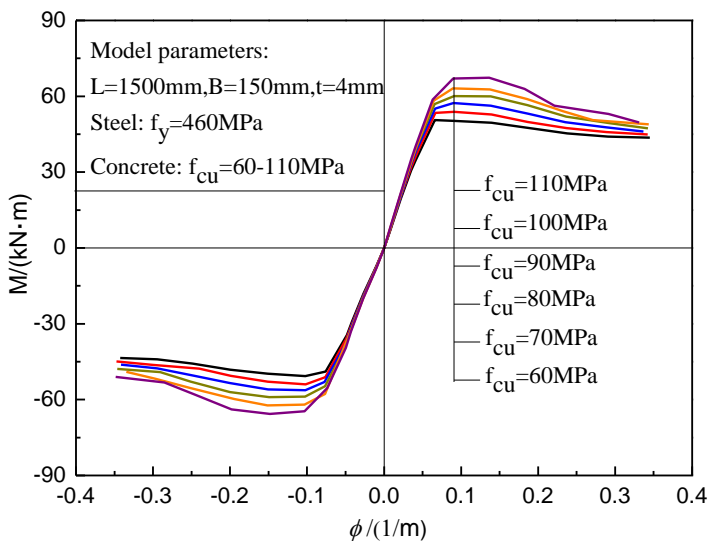

(b) Concrete compressive strength

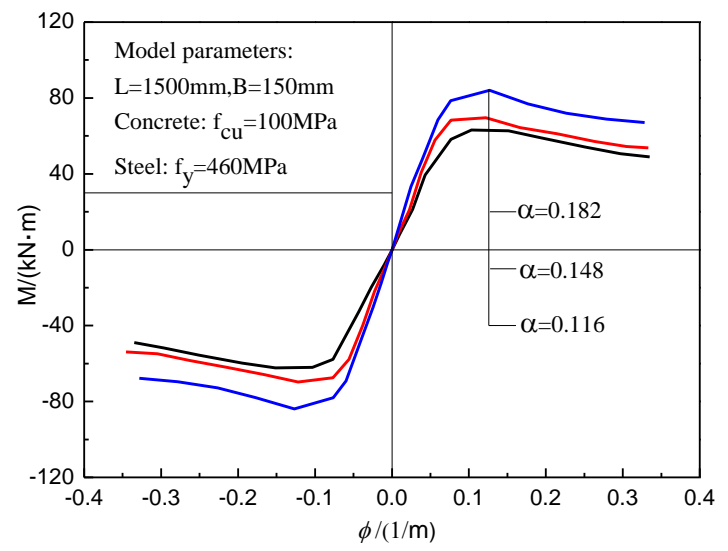

(c) Steel ratio

Fig. 26 Effects of $\mathrm{M}-\varphi$ envelope curves with different parameters

\section{Code comparison}

\subsection{Ultimate flexural capacity}

The AISC-LRFD (2010) [37], AIJ (1997) [38], EC4 (2004) [39], GB50936 (2014) [40], and DBJ (2010) [41] design codes were adopted to calculate the theoretical ultimate flexural capacity of the HCFHST specimen, and the suitability of these design codes was analyzed. Table 4 presents the calculated experimental and simulated values. $M_{u e}$ represents the ultimate flexural capacity of the finite element analysis, and $M_{u c}$ represents the 
theoretical ultimate flexural capacity calculated using a design code.

Table 4 indicates that the results for the ultimate flexural capacity calculated using the EC4 (2004) and DBJ (2010) design codes were higher than the experimental/simulated values by $16.7 \%$ and $18 \%$, respectively. The values of the ultimate flexural capacity calculated using the GB50936 (2014) design code were higher than the experimental/simulated values by slightly more than 20\%. Consequently, the calculations of the AISC (2010) and AIJ (1997) design codes were only $3.4 \%$ higher than the experimental/simulated values. Thus, the AISC (2010) and AIJ (1997) design codes were the most suitable for calculating the ultimate flexural capacity of the HCFHST members under pure bending.

\subsection{Flexural stiffness}

The initial flexural stiffness of CFSTs under pure bending is usually confirmed as the stiffness at $\mathrm{M}=0.2 M_{u e}$. At this moment, the deformations of the CFST are completely linear elastic, because the concrete has yet to crack or is just beginning to crack in the tensile zones. The serviceability-level flexural stiffness of the CFST is confirmed as its stiffness at $\mathrm{M}=0.6 M_{u e}$; according to the $\mathrm{M}-\varphi$ curve, the member was still in the elastic stage at this load level.

The flexural stiffness of an HCFHST member is evaluated via its initial and serviceability-level flexural stiffness. The design codes of different countries for calculating the flexural stiffness are different, in which, the concrete and the steel tube of CFST members are generally assumed to contribute independently to the overall stiffness of the members. Hence, the basic equation for calculating the stiffness of an HCFHST member is

$$
K_{e}=m E_{s} I_{s}+n E_{c} I_{c}
$$

Where, $E_{s}$ and $E_{c}$ are the elastic moduli of the steel tube and concrete, respectively; $I_{s}$ and $I_{c}$ are the second moment of area for the steel tube and the gross concrete section, respectively; and $m$ and $n$ are the contribution coefficients of the flexural stiffness.

The AIJ (1997), EC4 (2004), and AISC-LRFD (2010) design codes have the same values of $m$ but different values of $n$, whereas the BS5400 (2005) [42] design code simultaneously accounts for the effects of the steel material and concrete on the flexural stiffness of CFSTs. The flexural stiffness calculations of each design code are given as follows.

1) AISC-LRFD (2010)

$K_{e}=E_{s} I_{s}+0.8 E_{c} I_{c}$

Where $E_{s}=210000(\mathrm{MPa})$ and $E_{c}=4700 \sqrt{f_{c}^{\prime}}(\mathrm{MPa})$.

2) AIJ (1997)

$K_{e}=E_{s} I_{s}+0.2 E_{c} I_{c}$

Where $E_{s}=205800(\mathrm{MPa})$ and $E_{c}=21000 \sqrt{f_{c}^{\prime} / 19.6}(\mathrm{MPa})$.

3) $\mathrm{EC} 4(2004)$

$K_{e}=E_{s} I_{s}+0.6 E_{c} I_{c}$

Where $E_{s}=210000(\mathrm{MPa})$ and $E_{c}=22000 \cdot\left(f_{c}^{\prime} / 10\right)^{0.3}(\mathrm{MPa})$.

\section{Table 4}

Comparisons between the experimental/simulated values and the design code values

\begin{tabular}{|c|c|c|c|c|c|c|c|c|c|c|c|c|c|}
\hline \multirow[b]{2}{*}{ Type } & \multirow[b]{2}{*}{ specimen } & \multirow[b]{2}{*}{$\alpha$} & \multirow{2}{*}{$\begin{array}{c}f_{c u} \\
\text { (MPa) }\end{array}$} & \multirow{2}{*}{$\begin{array}{c}f_{y} \\
(\mathrm{MPa})\end{array}$} & \multirow{2}{*}{$\begin{array}{c}M_{u e} \\
(\mathrm{kN} \cdot \mathrm{m})\end{array}$} & \multicolumn{2}{|c|}{ AISC/ AIJ } & \multicolumn{2}{|l|}{$\mathrm{EC} 4$} & \multicolumn{2}{|l|}{ GB50936 } & \multicolumn{2}{|l|}{ DBJ } \\
\hline & & & & & & $\begin{array}{c}M_{u c} \\
(\mathrm{kN} \cdot \mathrm{m})\end{array}$ & $\begin{array}{l}M_{u c} \\
/ M_{u e}\end{array}$ & $\begin{array}{c}M_{u c} \\
(\mathrm{kN} \cdot \mathrm{m})\end{array}$ & $\begin{array}{l}M_{u c} \\
/ M_{u e}\end{array}$ & $\begin{array}{c}M_{u c} \\
(\mathrm{kN} \cdot \mathrm{m})\end{array}$ & $\begin{array}{l}M_{u c} \\
/ M_{u e}\end{array}$ & $\begin{array}{c}M_{u c} \\
(\mathrm{kN} \cdot \mathrm{m})\end{array}$ & $\begin{array}{l}M_{u c} \\
/ M_{u e}\end{array}$ \\
\hline \multirow[t]{6}{*}{ Test } & SPB1-1 & 0.116 & 95 & 434.56 & 55.65 & 54.73 & 0.98 & 63.19 & 1.14 & 72.95 & 1.31 & 65.09 & 1.17 \\
\hline & SPB1-2 & 0.116 & 95 & 434.56 & 58.49 & 54.73 & 0.94 & 63.19 & 1.08 & 72.95 & 1.25 & 65.09 & 1.11 \\
\hline & SPB2-1 & 0.148 & 95 & 416.31 & 67.62 & 65.09 & 0.96 & 73.56 & 1.09 & 81.52 & 1.21 & 76.62 & 1.13 \\
\hline & SPB2-2 & 0.148 & 95 & 416.31 & 67.05 & 65.09 & 0.97 & 73.56 & 1.10 & 81.52 & 1.22 & 76.62 & 1.14 \\
\hline & SPB3-1 & 0.182 & 95 & 436.91 & 83.27 & 81.41 & 0.98 & 89.83 & 1.08 & 93.73 & 1.13 & 94.60 & 1.14 \\
\hline & SPB3-2 & 0.182 & 95 & 436.91 & 82.82 & 81.41 & 0.98 & 89.83 & 1.08 & 93.73 & 1.13 & 94.60 & 1.14 \\
\hline \multirow[t]{15}{*}{ FEA } & ASPB-1 & 0.116 & 100 & 460 & 62.72 & 57.94 & 0.92 & 66.88 & 1.07 & 77.24 & 1.23 & 68.89 & 1.10 \\
\hline & ASPB-2 & 0.116 & 100 & 550 & 69.22 & 69.27 & 1.00 & 79.01 & 1.14 & 87.98 & 1.27 & 79.57 & 1.14 \\
\hline & ASPB-3 & 0.116 & 100 & 690 & 78.08 & 86.91 & 1.11 & 97.66 & 1.25 & 104.68 & 1.34 & 96.06 & 1.23 \\
\hline & ASPB-4 & 0.116 & 100 & 770 & 82.96 & 96.98 & 1.17 & 108.24 & 1.30 & 114.27 & 1.38 & 105.48 & 1.27 \\
\hline & ASPB-5 & 0.116 & 100 & 890 & 90.48 & 112.10 & 1.24 & 124.02 & 1.37 & 128.73 & 1.42 & 119.65 & 1.32 \\
\hline & ASPB-6 & 0.116 & 100 & 960 & 95.07 & 120.91 & 1.27 & 133.19 & 1.40 & 137.23 & 1.44 & 127.96 & 1.35 \\
\hline & ASPB-7 & 0.116 & 60 & 460 & 50.47 & 57.94 & 1.15 & 64.44 & 1.28 & 66.82 & 1.32 & 62.54 & 1.24 \\
\hline & ASPB-8 & 0.116 & 70 & 460 & 53.86 & 57.94 & 1.08 & 65.15 & 1.21 & 69.50 & 1.29 & 64.15 & 1.19 \\
\hline & ASPB-9 & 0.116 & 80 & 460 & 56.82 & 57.94 & 1.02 & 65.79 & 1.16 & 72.13 & 1.27 & 65.76 & 1.16 \\
\hline & ASPB-10 & 0.116 & 90 & 460 & 59.46 & 57.94 & 0.97 & 66.37 & 1.12 & 74.71 & 1.26 & 67.35 & 1.13 \\
\hline & ASPB-11 & 0.116 & 110 & 460 & 66.50 & 57.94 & 0.87 & 67.36 & 1.01 & 79.71 & 1.20 & 70.38 & 1.06 \\
\hline & ASPB-12 & 0.148 & 100 & 460 & 69.64 & 71.93 & 1.03 & 81.04 & 1.16 & 88.74 & 1.27 & 84.00 & 1.21 \\
\hline & ASPB-13 & 0.182 & 100 & 460 & 83.98 & 85.72 & 1.02 & 94.60 & 1.13 & 98.42 & 1.17 & 99.67 & 1.19 \\
\hline & \multicolumn{5}{|l|}{ Mean value } & \multicolumn{2}{|c|}{1.034} & \multicolumn{2}{|c|}{1.167} & \multicolumn{2}{|c|}{1.269} & \multicolumn{2}{|c|}{1.180} \\
\hline & \multicolumn{5}{|c|}{ Standard Deviation (COV) } & \multicolumn{2}{|c|}{0.108} & \multicolumn{2}{|c|}{0.107} & \multicolumn{2}{|c|}{0.087} & \multicolumn{2}{|c|}{0.075} \\
\hline
\end{tabular}


4) BS5400 (2005)

$$
K_{e}=0.95 E_{s} I_{s}+0.45 E_{c} I_{c}
$$

Where $E_{s}=206000(\mathrm{MPa})$ and $E_{c}=450 f_{c u}(\mathrm{MPa})$.

The initial and serviceability-level flexural stiffness of the test are compared with the results obtained using the design codes in Tables 5 and 6, respectively.

As shown in Table 5, the initial flexural stiffness values calculated using the various design codes were larger than the experimental results, except for the values obtained from AIJ (1997) design code, which were a little lower than the experimental results. The flexural stiffness values calculated using BS5400 (2005) design code were the closest to the experimental results, as the mean and standard deviation of the $\mathrm{K}_{\mathrm{ic}} / \mathrm{K}_{\mathrm{ie}}$ ratios were 1.038 and 0.089 , respectively. The flexural stiffness values calculated using the AIJ (1997) design code were the second-closest; on average, they were only $5.7 \%$ lower than the experimental values. The flexural stiffness values calculated using the AISC (2010) and EC4 (2004) design codes were $29.8 \%$ and $16.8 \%$ higher than the experimental values, respectively.

Table 6 indicates that the serviceability-level flexural stiffness calculated using AIJ (1997) and BS5400 (2005) design codes were in better accordance with the experimental values than the values calculated by the other codes, as the results for AIJ (1997) and BS5400 (2005) were 26\% and 38.3\% higher than the experimental values, respectively. The serviceability-level flexural stiffness values calculated using the AISC (2010) and EC4 (2004) design codes differed significantly from the experimental values; they were $73 \%$ and $55 \%$ higher than the experimental values, respectively.

According to the foregoing results, the BS5400 (2005) and AIJ (1997) design codes can be used to satisfy design requirements for the initial and serviceability-level flexural stiffness of HCFHST members, whereas the AISC (2010) and EC4 (2004) design codes are not suitable for estimating the serviceability-level flexural stiffness of HCFHST members.

Table 5

Comparisons between the experiment results and predicted values for the initial flexural stiffness

\begin{tabular}{|c|c|c|c|c|c|c|c|c|c|}
\hline \multirow{2}{*}{ specimen } & \multirow{2}{*}{$K_{i e}$} & \multicolumn{2}{|c|}{ AISC } & \multicolumn{2}{|c|}{ AIJ } & \multicolumn{2}{|c|}{ EC4 } & \multicolumn{2}{|c|}{ BS5400 } \\
\hline & & $K_{i c}$ & $K_{i c} / K_{i e}$ & $K_{i c}$ & $K_{i c} / K_{i e}$ & $K_{i c}$ & $K_{i c} / K_{i e}$ & $K_{i c}$ & $K_{i c} / K_{i e}$ \\
\hline SPB1-1 & 2396 & 2932 & 1.22 & 2009 & 0.84 & 2560 & 1.07 & 2277 & 0.95 \\
\hline SPB1-2 & 2416 & 2932 & 1.21 & 2009 & 0.83 & 2560 & 1.06 & 2277 & 0.94 \\
\hline SPB2-1 & 2615 & 3259 & 1.25 & 2377 & 0.91 & 2945 & 1.13 & 2607 & 1.00 \\
\hline SPB2-2 & 2439 & 3259 & 1.34 & 2377 & 0.97 & 2945 & 1.21 & 2607 & 1.07 \\
\hline SPB3-1 & 2644 & 3573 & 1.35 & 2730 & 1.03 & 3276 & 1.24 & 2923 & 1.11 \\
\hline SPB3-2 & 2520 & 3573 & 1.42 & 2730 & 1.08 & 3276 & 1.30 & 2923 & 1.16 \\
\hline Mean value & & \multicolumn{2}{|c|}{1.298} & \multicolumn{2}{|c|}{0.943} & \multicolumn{2}{|c|}{1.168} & \multicolumn{2}{|c|}{1.038} \\
\hline Standard & & \multicolumn{2}{|c|}{0.084} & \multicolumn{2}{|c|}{0.102} & \multicolumn{2}{|c|}{0.097} & \multicolumn{2}{|c|}{0.089} \\
\hline
\end{tabular}

Note: $K_{i e}$ and $K_{s e}$ are the values of the initial and serviceability-level flexural stiffness, respectively, obtained from the experiments. $K_{i c}$ and $K_{s c}$ are the values of the initial and serviceability-level flexural stiffness, respectively, calculated using a design code.

Table 6

Comparisons between the experiment results and predicted values for the serviceability-level flexural stiffness

\begin{tabular}{|c|c|c|c|c|c|c|c|c|c|}
\hline \multirow{2}{*}{ specimen } & \multirow{2}{*}{$K_{s e}$} & \multicolumn{2}{|c|}{ AISC } & \multicolumn{2}{|c|}{ AIJ } & \multicolumn{2}{|c|}{$\mathrm{EC} 4$} & \multicolumn{2}{|c|}{ BS5400 } \\
\hline & & $K_{s c}$ & $K_{s c} / K_{s e}$ & $K_{s c}$ & $K_{s c} / K_{s e}$ & $K_{s c}$ & $K_{s c} / K_{s e}$ & $K_{s c}$ & $K_{s c} / K_{s e}$ \\
\hline SPB1-1 & 1721 & 2932 & 1.70 & 2009 & 1.17 & 2560 & 1.49 & 2277 & 1.32 \\
\hline SPB1-2 & 1800 & 2932 & 1.63 & 2009 & 1.12 & 2560 & 1.42 & 2277 & 1.27 \\
\hline SPB2-1 & 1866 & 3259 & 1.75 & 2377 & 1.27 & 2945 & 1.58 & 2607 & 1.40 \\
\hline SPB2-2 & 1820 & 2010 & 1.79 & 2377 & 1.31 & 2945 & 1.62 & 2607 & 1.43 \\
\hline SPB3-1 & 1969 & 3573 & 1.81 & 2730 & 1.39 & 3276 & 1.66 & 2923 & 1.48 \\
\hline SPB3-2 & 2094 & 3573 & 1.71 & 2730 & 1.30 & 3276 & 1.56 & 2923 & 1.40 \\
\hline \multicolumn{2}{|l|}{ Mean value } & \multicolumn{2}{|c|}{1.732} & \multicolumn{2}{|c|}{1.260} & \multicolumn{2}{|c|}{1.555} & \multicolumn{2}{|c|}{1.383} \\
\hline \multicolumn{2}{|c|}{ Standard Deviation (COV) } & \multicolumn{2}{|c|}{0.066} & \multicolumn{2}{|c|}{0.099} & \multicolumn{2}{|c|}{0.088} & \multicolumn{2}{|c|}{0.076} \\
\hline
\end{tabular}

\section{Conclusions}

This paper has mainly studied the seismic performance of HCFHST members subjected to cyclic pure bending. Six specimens were tested and thirteen finite-element models were developed to analyze the effect of different parameters on the bearing capacity and flexural stiffness of HCFHSTs. Based on the comparison with different codes, suggestions for the design of the initial and serviceability-level flexural stiffness were proposed. The following conclusions were obtained from this study.
1) HCFHST members subjected to cyclic pure bending loads exhibit excellent seismic performance. The hysteretic curves of HCFHST members are plump in shape and have no obvious pinch phenomenon. Furthermore, the load versus displacement curves do not decrease significantly after the applied load reaches the peak load, indicating that these members have excellent ductility performance. Additionally, throughout the loading process, HCFHST specimens do not exhibit significant strength degradation.

2) Increases in the steel ratio of HCFHST specimens lead to significant increases in the bearing capacity and energy dissipation capacity. When the 
steel ratio was increased from 0.116 to 0.182 , the peak load and energy dissipation capacity of HCFHST members increased by $45 \%$ and $17.4 \%$, respectively. However, the stiffness degradations of the specimens were not significantly affected by changes in the steel ratio.

3) Numerical analyses indicated that increases in the steel yield strength significantly improved the bearing capacity, yield moment, and ultimate moment of HCFHST members but hardly affected the stiffness in the elastic stage. Changes in the compressive strength of the concrete only slightly affected the elastic stiffness and yield moment of the HCFHST members. However, increases in the concrete strength increased the brittleness of the specimens, which reduced the ductility. Changes in the steel ratio of the members significantly affected the elastic stiffness and yield moment.

4) Comparison between design codes: Regarding the ultimate flexural capacity, the AISC (2010) and AIJ (1997) design codes were the most suitable codes for calculating the ultimate flexural capacity of HCFHSTs, as the

\section{References}

[1] Mursi, M. and Uy, B., "Strength of slender concrete filled high strength steel box columns", Journal of Constructional Steel Research, 2004, 60(12), pp. 1825-1848.

[2] Li, G. C., Yang, Z. J., and Lang Y. "Experimental behavior of high strength concrete-filled square steel tube under bi-axial eccentric loading", Advanced Steel Construction, 2010, 6(4), pp. 963-975.

[3] Li, G. C., Di, C. Y., Tian, L. and Fang, C., "Nonlinear finite element analysis on long columns of high-strength concrete-filled square steel tube with inner CFRP circular tube under axial load", Advanced Steel Construction, 2013, 9(2), pp. 124-138.

[4] Li, G. C., Yang, Z. J., Lang, Y. and Fang, C., "Behaviour of high strength concrete filled square steel tubular columns with inner CFRP circular tube under bi-axial eccentric loading", Advanced Steel Construction, 2013, 9, pp. 231-246.

[5] Portolés, J. M., Romero, M. L., Filippou, F. C. and Bonet, J. L., "Simulation and design recommendations of eccentrically loaded slender concrete-filled tubular columns", Engineering Structures, 2011, 33(5), pp. 1576-1593.

[6] Abramski, M., "Load-carrying capacity of axially loaded concrete-filled steel tubular columns made of thin tubes", Archives of Civil and Mechanical Engineering, 2018, 18(3), pp. 902-913.

[7] Ouyang, Y. and Kwan, A. K. H., "Finite element analysis of square concrete-filled steel tube (CFST) columns under axial compressive load", Engineering Structures, 2018, 156, pp. 443-459.

[8] Elchalakani, M., Zhao, X. L. and Grzebieta, R. H., "Concrete-filled circular steel tubes subjected to pure bending", Journal of constructional steel research, 2001, 57(11), pp. 1141-1168.

[9] Elchalakani, M., Karrech, A., Hassanein, M. F. and Yang, B., "Plastic and yield slenderness limits for circular concrete filled tubes subjected to static pure bending", Thin-Walled Structures, 2016, 109, pp. 50-64.

[10] Lu, F. W., Li, S. P., Li, D. W. and Sun, G. J., "Flexural behavior of concrete filled non-uni-thickness walled rectangular steel tube", Journal of Constructional Steel Research, 2007, 63(8), pp. 1051-1057.

[11] Chitawadagi, M. V. and Narasimhan, M. C., "Strength deformation behaviour of circular concrete filled steel tubes subjected to pure bending", Journal of Constructional Steel Research, 2009, 65(8-9), pp. 1836-1845.

[12] Moon, J., Roeder, C. W., Lehman, D. E. and Lee, H. E., "Analytical modeling of bending of circular concrete-filled steel tubes", Engineering Structures, 2012, 42, pp. 349-361.

[13] Zha, X. X., Gong, G. B. and Liu, X. C., "Study on behavior of concrete filled elliptical steel tube members part II: under bending and eccentric compression", Advanced Steel Construction, 2013, 9(2) pp. 108-123.

[14] Wang, R., Han, L. H., Nie, J. G. and Zhao, X. L., "Flexural performance of rectangular CFST members", Thin-Walled Structures, 2014, 79, pp. 154-165.

[15] Montuori, R. and Piluso, V., "Analysis and modelling of CFT members: moment curvature analysis”, Thin-Walled Structures, 2015, 86, pp. 157-166.

[16] Wang, Q. L. and Shao, Y. B., "Flexural performance of circular concrete filled CFRP-steel tubes", Advanced Steel Construction, 2015, 11(2), pp. 127-149.

[17] Fu, Z. Q., Ji, B. H., Maeno, H., Eizien, A. and Chen, J. S., "Flexural behavior of lightweight aggregate concrete filled steel tube", Advanced Steel Construction, 2014, 10(4), pp. 385-403.

[18] Xu, W., Han, L. H. and Li, W., "Performance of hexagonal CFST members under axial compression and bending", Journal of Constructional Steel Research, 2016, 123, pp. $162-175$.

[19] Li, G. C., Liu, D., Yang, Z. J. and Zhang, C. Y., "Flexural behavior of high strength concrete filled high strength square steel tube", Journal of Constructional Steel Research, 2017, 128, pp. $732-744$.

[20] Xiong, M. X., Xiong, D. X. and Liew, J. Y. R., "Flexural performance of concrete filled tubes with high tensile steel and ultra-high strength concrete", Journal of Constructional estimates of these design codes were only $3.4 \%$ higher than the values of ultimate flexural capacity obtained from tests and simulations. Regarding the flexural stiffness, the BS5400 (2005) and AIJ (1997) design codes can be used to satisfy the design requirements for the initial flexural stiffness and serviceability-level flexural stiffness of HCFHST members, whereas the AISC (2010) and EC4 (2004) design codes are not suitable for estimating the serviceability-level flexural stiffness of HCFHST members.

\section{Acknowledgements}

This project was supported by National Key R\&D Program of China (2018YFC0705704), Fundamental Research Project of Higher Education in Liaoning Province (LJZ2017004) and Liaoning Climbing Scholar Support Program (2018-0101).

Steel Research, 2017, 132, pp. 191-202.

21] Xie, L., Chen, M. C., Sun, W. and Yuan, F. "Behaviour of concrete-filled steel tubula members under pure bending and acid rain attack: Test simulation", Advances in Structural Engineering, 2019, 22(1), pp. 240-253.

[22] Chen, Y., Feng, R. and Wang, L. P., "Flexural behaviour of concrete-filled stainless steel SHS and RHS tubes", Engineering Structures, 2017, 134, pp. 159-171.

[23] Chen, Y., Feng, R. and Gong, W. Z., "Flexural behavior of concrete-filled aluminum alloy circular hollow section tubes", Construction and Building Materials, 2018, 165, pp $173-186$

[24] Han, L. H., You, J. T. and Lin, X. K., "Experimental behaviour of self-consolidating concrete (SCC) filled hollow structural steel (HSS) columns subjected to cyclic loadings", Advances in Structural Engineering, 2005, 8(5), pp. 497-512.

[25] Han, L. H. and Yang, Y. F., "Cyclic performance of concrete-filled steel CHS columns under flexural loading", Journal of Constructional Steel Research, 2005, 61(4), pp. 423-452.

[26] Han, L. H., Huang, H., Tao, Z. and .Zhao, X. L., "Concrete-filled double skin steel tubular (CFDST) beam-columns subjected to cyclic bending", Engineering Structures, 2006 , 28(12), pp. 1698-1714

[27] Han, L. H., Huang, H. and Zhao, X. L., "Analytical behaviour of concrete-filled double skin steel tubular (CFDST) beam-columns under cyclic loading", Thin-walled structures, 2009 47(6-7), pp. 668-680.

[28] Elchalakani, M. and Zhao, X. L., "Concrete-filled cold-formed circular steel tubes subjected to variable amplitude cyclic pure bending", Engineering Structures, 2008, 30(2), pp. 287-299

[29] Liao, F. Y., Han, L. H., Tao, Z. and ASCE, M., "Experimental behavior of concrete-filled stainless steel tubular columns under cyclic lateral loading", Journal of Structural Engineering, 2016, 143(4), pp. 04016219

[30] Serras, D. N., Skalomenos, K. A., Hatzigeorgiou, G. D. and Beskos, D. E., "Modeling of circular concrete-filled steel tubes subjected to cyclic lateral loading", Structures, 2016, 8 pp. 75-93.

[31] Chen, Y. Y., Li, W. and Fang, C., "Performance of partially encased composite beams under static and cyclic bending", Structures, 2017, 9, pp. 29-40.

[32] Ma, D. Y., Han, L. H., Ji, X. D. and Yang, W. B., "Behaviour of hexagonal concrete-encased CFST columns subjected to cyclic bending", Journal of Constructional Steel Research, 2018, 144, pp. 283-294.

[33] GB/T228-2010. Metallic Materials - Tensile Testing at Ambient Temperature, Beijing, China, 2010.

[34] GB/T50081-2002. Standard for test method of mechanical properties on ordinary concrete, Beijing, China, 2002

[35] Han, L. H., Yao, G. H. and Tao, Z., "Performance of concrete-filled thin-walled steel tubes under pure torsion", Thin-walled structures, 2007, 45(1), pp. 24-36.

[36] Li, W., Han, L. H. and Chan, T. M., "Numerical investigation on the performance of concrete-filled double-skin steel tubular members under tension", Thin-walled structures, 2014, 79, pp. 108-118.

[37] ANSI/AISC 360-10, Specification for Structural Steel Buildings, American Institute of Steel Construction, Chicago-Illinois, 2010.

[38] AIJ, Recommendations for design and construction of concrete filled steel tubular structures, Architectural Institute of Japan, Tokyo, Japan, 1997.

[39] Eurocode 4, Design of Composite Steel and Concrete Structures-Part 1-1: General Rules and Rules for Buildings, European Committee for Standardization, Brussels, 2004.

[40] GB50936-2014, Technical Code for Concrete filled Steel Tubular Structures, Ministry of Housing and Urban-Rural Development of the People's Republic of China, Chin Architecture \& Building Press, Beijing, China, 2014.

[41] DBJ13-51-2010. Technical code of concrete-filled steel tubular structures, Fuzhou, Fujian; China, 2010.

[42] BS5400, Steel, Concrete and Composite Bridges - Part 5: Code of Practice for Design of Composite Bridges, British Standards Institution, London, 2005. 